\title{
Structural Identification and Electrical Conductivity Analysis of Sodium Hypophosphate Mixed Blend Polymer Electrolytes
}

\author{
K. Jeyabanu, P. Devendran, S. Asath Bahadur, N. Nallamuthu
}

\begin{abstract}
Sodium hypophosphate is mostly applicable for improving protonic ion movement in the materials. Easy water absorbent blend polymers of poly vinyl-chloride and poly vinyl -pyrrolidone are mixed with sodium hypophosphate for using as polymeric membrane of electrochemical device applications. The various composition of solid electrolytes are prepared by solution casting techniques. Structural functional group of prepared materials of polymer matrices are characterized through FTIR spectroscopy. The electrical conductivity of the sample is determined through measured cole-cole plot of impedance data at different temperatures. The maximum electrical conductivity is calculated in the order of $10^{-6} \mathrm{Scm}^{-1}$.
\end{abstract}

Keywords-Solid electrolyte, PVA, PVP, FTIR, Impedance, Activation energy

\section{INTRODUCTION}

$\mathrm{E}$ nergy with unpolluted required for regular life style of human being, reduction of poverty expansion and well growth of economy in whole world. Now a days, energy conversion systems i.e conventional energy sources are used as easy way for consumption which has a snag of producing polluted gases like carbon di oxide, sulphur etc[1]. Due to less availability of the conventional sources suchas fossil fuels, coal, gas, etc., electrochemical energy systems are acceptable as a environmentally and economically creation of renewable energy sources. The best suitable energy conversion electrochemical energy sources are batteries, fuel cells and supercapacitors [2-5]. In which, various kinds of solid state batteries are more acceptable in electronic devices applications. In all types of electrochemical devices, solid electrolyte is very much essential component to gain its properties technologically [6-9]. It should posses highly inherent properties such as best ionic conductivity $\left(\sigma \geq 10^{-3}\right.$

\footnotetext{
Revised Manuscript Received on December 17, 2019.

* Correspondence Author

N. Nallamuthu*, Department of Physics, Kalasalingam Academy of Research and Education, Krishnankoil - 626126. Tamil Nadu, India.

Email: n.nallamuthu@klu.ac.in

K. Jeyabanu, Department of Physics, Kalasalingam Academy of Research and Education, Krishnankoil - 626126.Tamil Nadu, India. Email: jeyabanu.gajendran@gmail.com

P. Devendran, Department of Physics, Kalasalingam Academy of Research and Education, Krishnankoil - 626126.Tamil Nadu, India. Email: pdevavenmani@gmail.com

S. Asath Bahadur, Department of Physics, Kalasalingam Academy of Research and Education, Krishnankoil - 626126.Tamil Nadu, India. Email:
} s_a_bahadur@yahoo.co.in
$\mathrm{Scm}^{-1}$ ) which is closest to the ionic conductivity of liquid electrolyte, Ion transference number $\left(t_{\text {ion }}\right)$ should be nearest one, highly chemical, thermal and electrochemical stabilities, high mechanical strength and it should be compatibility with electrode materials [10-12]. Due to the remarkable properties such as fabricating flexibility, easy formation, less weight and more chemical and thermal stability with long shelf life at operational temperature solid polymer electrolytes are more employed for solid state primary and secondary batteries, asymmetric and symmetric supercapacitors and also DMFC and Proton exchange membrane fuel cells, etc[13]. Different categories of ionic conducting namely $\mathrm{H}^{+}, \mathrm{Na}^{+}, \mathrm{Li}^{+}, \mathrm{K}^{+}, \mathrm{Cu}^{+}$, $\mathrm{Ag}^{+}$, etc., films are involved the growth of electrochemical devices. More metal phosphates make best acceptable $\mathrm{OH}$ groups and forming less oxygen deficiency which improves the better protonic conductivity. Various challenges adopted to produce polymer electrolyte such as synthesizing new polymer, blending two or more polymers, cross linking polymer, adding plasticizers to polymer, using phase inversion method, adding metal salt in polymer, adding some inorganic fillers in polymer matrices to increase amorphous nature. Amoung all, Blending polymers are enhanced the ionic conductivity inaddition to decreasing poor mechanical stability, solvent volatility and chemical instability. PVA blended PVP polymers are providing more effectiveness as solid electrolyte [14].

Here, we aimed to synthesis PVA and PVP blended polymer matrices incorporated with sodium hypophosphate salt in different composition to enhance the electric properties of film. The synthesized films are structurally characterized by FTIR and analysed its dielectric properties.

\section{EXPERIMENTAL}

\section{A. Sample preparation}

Polymer blend electrolytes in Stoichiometric ratio of $50 \mathrm{wt} \%$ of polyvinyl-alcohol and $50 \mathrm{wt} \%$ ofpolyvinyl- pyrrolidone and $\mathrm{x}$ wt $\%(1,2,3,4$ and 5) sodium hypo phosphate are synthesized by solution casting method. Due to different compositions, PVA and PVP powders are dissolved by distilled water individually. These are named as A and B. Sodium hypo phosphate $\left(\mathrm{NaH}_{2} \mathrm{PO}_{4}\right)$ is also made as aqueous solution which is named as $\mathrm{C}$.

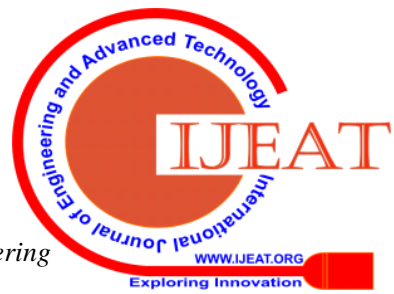




\section{Structural Identification and Electrical Conductivity Analysis of Sodium Hypophosphate Mixed Blend Polymer Electrolytes}

All the precursor solutions are added in $100 \mathrm{ml}$ beaker and stirrred with continuously to obtain transparent solution. The final transparent solution is stirred constantly with maintain temperature $60{ }^{\circ} \mathrm{C}$. The sol is become as gel and it is kept in oven to dry. The dried film formed as film are characterised by several methods. X-ray Diffraction showed the amorphous nature for all the dried salt mixed blend polymer films. The structural identification are analysed using Fourier transform Infrared spectroscopy methods.

\section{RESULTS AND DISCUSSION}

\section{A. Fourier Transform Infrared spectroscopy}

The structural identification and formed functional groups are analysed using Fourier Transform Infrared spectroscopy analysis. Transmittance spectra of FTIR is examined using "SHIMADZU IR tracer 100" spectrometer with resolution of $4 \mathrm{~cm}^{-1}$. The spectra is plotted in wavenumber region of $4000 \mathrm{~cm}^{-1}$

to $400 \mathrm{~cm}^{-1}$

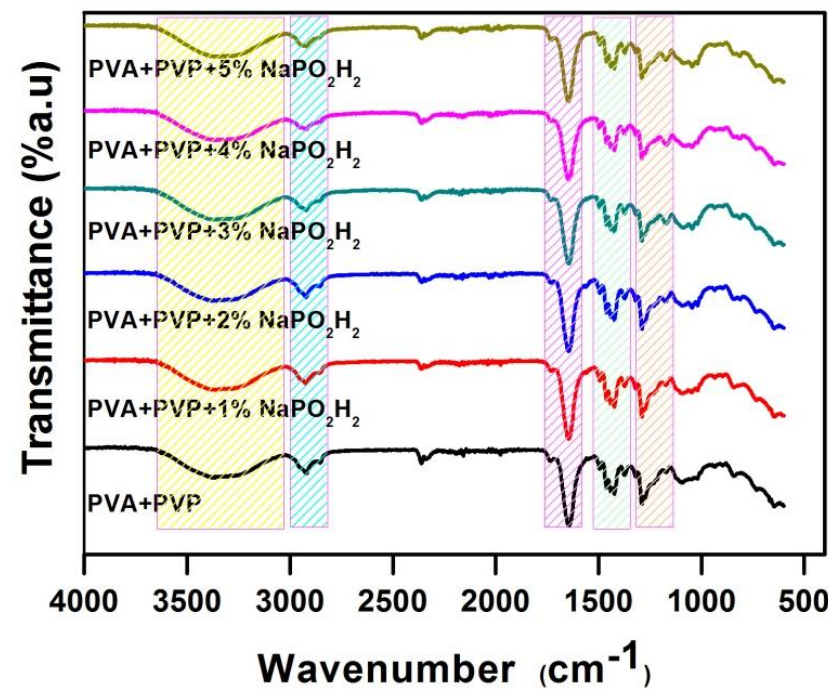

Fig.1. FTIR spectra for various composition of sodium hypo phosphate mixed blend polymer films.

The IR spectra of various composition of sodium hypophosphate mixed 50PVA:50PVP blend polymer is shown in Fig.1. The characteristic predominant $\mathrm{OH}$ stretching vibration broad band of pure PVA has been observed at the region of $3595-3065 \mathrm{~cm}^{-1}$ in the blend polymer electrolyte system. The observed bands at the region of $3000-2850 \mathrm{~cm}^{-1}$ is assigned to the characteristic vibration of $\mathrm{CH}$ and $\mathrm{CH}_{2}$ stretching of PVP matrix[15] The IR bands formed at 600 $850 \mathrm{~cm}^{-1}$ is ascribed as $\mathrm{C}-\mathrm{H}$ asymmetric stretching and $\mathrm{C}-\mathrm{H}$ rocking of pure PVA[16] and are shifted in the blend polymer system and its composition. The bands at the region at 1080 $\mathrm{cm}^{-1}$ is observed corresponds to C-O stretching of acetyl groups present on the PVA backbone [17]. In Figure 1, the obtained band at the region of $1400-1500 \mathrm{~cm}^{-1}$ is assigned to the characteristic vibration of $\mathrm{CH}$ deformation of cyclic $\mathrm{CH}_{2}$ groups [18]. The vibration band at the region of 1550-1700 $\mathrm{cm}^{-1}$ is attributed to Contribution from $\mathrm{C}=\mathrm{O}$ and $\mathrm{N}-\mathrm{C}$ of PVP [15]. The bands are slightly shifted towards lower frequencies in higher concentrations.

\section{B. Impedance spectroscopy}

Impedance spectroscopy deals with the microstructure of polymer materials. Fig. 2 shows the complex impedance plot of different composition of sodium hypo phosphate mixed PVA/PVP at the room temperature. These cole - cole plots of blended with polymer are showed inclined semicircle, which indicates non-Debye behavior in the materials. It is equivalent to the parallel combination of resistance and capacitance. For $1 \mathrm{wt} \%, 2 \mathrm{wt} \%$, $3 \mathrm{wt} \%$ and $5 \mathrm{wt} \%$ of sodium hypo phosphate mixed blend polymer matrices, one small inclined spike is started at lower frequencies. It is also equivalent to the capacitance serially connected with parallel combination of resistance and capacitance. The bulk resistance is determined from the intercept of the semicircle on the real axis at the lower frequency in cole-cole plot of complex impedance. The lowest bulk impedance is measured as $40617 \Omega$ for $5 \mathrm{wt} \%$ sodium hypophosphate mixed blend polymer system than other. By measured bulk resistance from fig. 2, the electrical conductivity of $\mathrm{NaPO}_{2} \mathrm{H}_{2}$ mixed polymer blend electrolytes is calculated using the method $\sigma=1 / \mathrm{RbA}$, where ' $\mathrm{l}$ ' the thickness of the film, 'A' the area of the film and $\mathrm{Rb}$ the bulk resistance of the material.

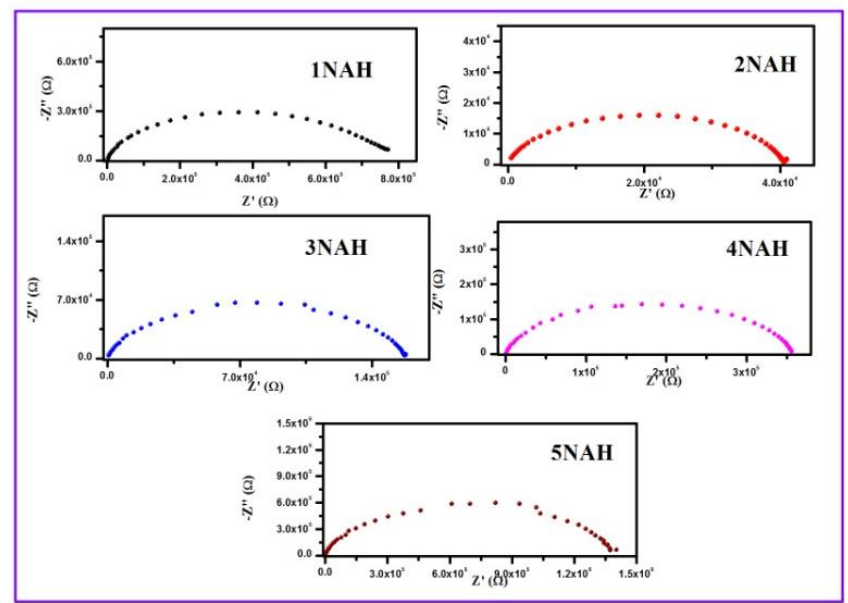

Fig.2. Cole - Cole plot for Various composition of sodium hypo phosphate mixed PVA and PVP blend polymer sample.

The electrical conductivity is calculated and $2 \mathrm{wt} \%$ sodium hypophosphate mixed blend polymer system is leading as $1.18 \times 10^{-6} \mathrm{Scm}^{-1}$ at ambient temperature.

The electrical conductivity is also plotted for different heat treated temperature for all composition of polymer matrices. The conductivity is raised while increasing temperature for all compositions. Fig.3. indicate $\log \sigma \mathrm{T}$ vs $1000 / \mathrm{T}$ plots for the various composition of sodium hypophosphate mixed PVA -PVP blend polymer systems. The activation energy is also calculated from the slope of the linear curve obtained in the plot.

Fig.3.shows that the plot of calculated electrical conductivity for various temperatures. It has showed straight line because of the increasing electrical conductivity. The activation energy is calculated by slope of straight line using the formula $\sigma \mathrm{T}=\sigma_{0}{ }^{*} \exp (-\mathrm{Ea} / \mathrm{KT})$. The activation energy is found to be $0.668557 \mathrm{eV}$ for $2 \mathrm{wt} \%$ sodium hypophosphate mixed PVA/PVP blend polymer electrolyte system. The obtained lower energy indicates the formed enough voids to 
improve high range movement of ions. Hence, the electrical conductivity is also obtained as maximum for this composition.

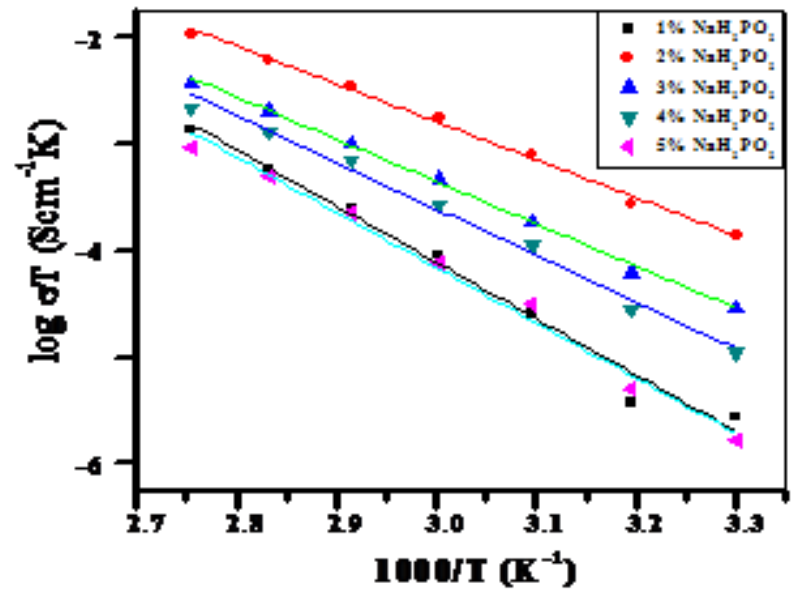

Fig.3. $\log \sigma \mathrm{T}$ vs $1000 / \mathrm{T}$ for all the composition of sodium hypophosphate mixed PVA/PVP blend polymer electrolyte.

\section{AC conductivity studies}

Fig. 4 . shows that $\log \sigma$ vs. $\log \omega$ plot obtained at different temperatures for of 50PVA/50PVP doped with different $\mathrm{wt} \%$ of $\mathrm{NaPO}_{2} \mathrm{H}_{2}$. From fig. 4., it is observed that the frequency dependence of conductivity shows two distinct regimes, within the measured frequency window, i) the low frequency plateau region and ii) high frequency dispersion region. The plateau region corresponds to frequency independent conductivity $\left(\sigma_{\mathrm{o}}\right)$ or $\sigma \mathrm{dc}$. The $\left(\sigma_{\mathrm{o}}\right)$ value is obtained by extrapolating the conductivity value to the zero frequency. The $\sigma_{\mathrm{dc}}$ value obtained from the conductivity vs. frequency plots at different composition was in range of $10^{-6}$ to $10^{-8}$ $\mathrm{Scm}^{-1}$, which is in good agreement with the dc conductivity obtained from the impedance analysis.

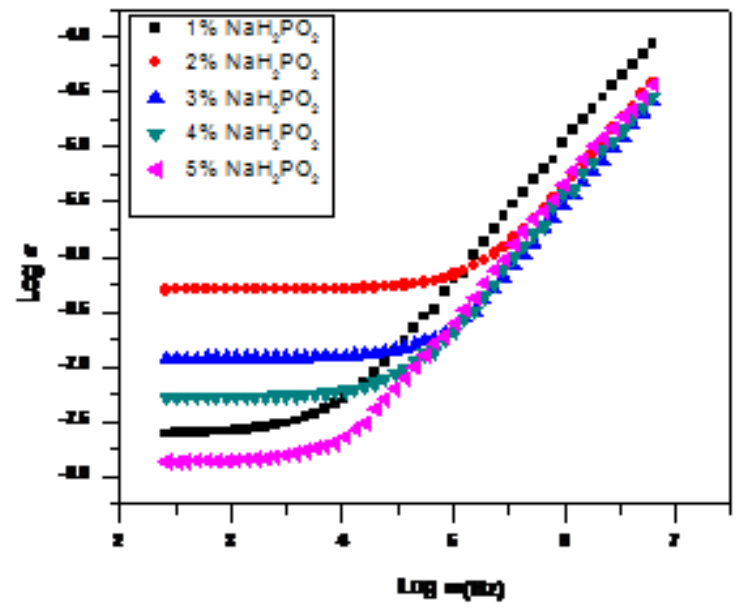

Fig.4. Conductivity as function of frequency plot for Various composition of sodium hypo phosphate mixed PVA and PVP blend polymer sample.

\section{CONCLUSION}

At various compositions of PVA and PVP mixed sodium hypo phosphate were synthesized by solution- casting method. The prepared samples are showed the amorphous nature for blend polymer and all the various composition of Sodium hypophasphate salt mixed blend polymer. IR bands are clearly identify the confirmation of functional groups in polymer electrolytes. The bulk impedance are also analysed by the obtained semicicrcles of cole-cole plot for all compositions. The electrical conductivity is calculated as maximum for $2 \mathrm{wt} \%$ sodium hypophosphate mixed polymers. It is found to be $1.18 \times 10^{-6} \mathrm{Scm}^{-1}$ at ambient temperature with activation energy $0.66 \mathrm{eV}$. Because of the formation of high electrical conductivity, it can be applicable as solid electrolyte for electrochemical device applications.

\section{ACKNOWLEDGMENT}

Author K.Jeyabanu and NNM thanks management of kalasalingam academy of research and education for providing the URF.

\section{REFERENCES}

[1] M. D. Slater, D. Kim, E. Lee, C. S. Johnson, "Sodium-ion batteries." Advanced Functional Materials vol. 23.8 (2013) pp 947-958.

[2] M.M. Doeff, Steven J.Visco, Yanping, Ma, Marcus Peng, Lei, Dung, Lutgard C. De Jonghe, Thin film solid state sodium batteries for electric vehicles. Electrochimica Acta, vol. 40 (1995) pp. 2205-2210.

[3] K. P. Radha, S. Selvasekarapandian, S. Karthikeyan, M. Hema, C. Sanjeeviraja, "Synthesis and Impedance analysis of proton conducting polymer electrolyte, Ionics, vol.19 (10) (2013) pp 1437-1447.

[4] M. Krumova, D. Lopez, R. Benavente, C. Mijangos, JM. Perena "Effect of crosslinking on themechanical and thermal properties of poly(vinyl alcohol)", Polymer, vol.41, pp. 9265-9272, 2000.

[5] K. Masuda, H. Kaji, F. Horii, "CP/MAS ${ }^{13} \mathrm{C}$ NMR analyses of hydrogen bonding and the chain conformation in the crystalline and noncrystalline regions for poly(vinyl alcohol) films", J Polym Sci Part B, Polym Phys, vol. 38:1, pp. 1-9, 2000

[6] Y.A. Badr, K.M.A. El-Kader, R.M. Khafagy, "Raman spectroscopy study of CdS, PVA composite films", J. Appl. polym.Sci. vol. 92, pp 1984-1992, 2004

[7] K.M.A. El-Kader, A.S. Orabi, "Spectroscopic behavior of poly(-vinyl alcohol) films with different molecular weights", Polym. Test. Vol.21, pp. 591-595, 2002.

[8] F. El-Tantawy, K.M. Abdel-Kader, F. Kaneko, Y.K. Sung, "Physical properties of CdS-poly (vinyl alcohol) nanoconducting composite synthesized by organosol techniques and novel application potential", Eur. Polym. J. vol. 40, pp. 415-430 (2004)

[9] M. Krumova, D. Lopez, R. Benavente, C. Mijangos, J.M. Perena "Effect of crosslinking on the mechanical and thermal properties of poly(vinyl alcohol). Polymer" vol. 41, pp. 9265-9272, 2000.

[10] M. Suzuki, T. Yoshida, T. Koyama, S. Kobayashi, M. Kimura, K. Hanabusa, H. Shirai, "Ionic conduction in partially phosphorylated poly(vinyl alcohol) as polymer electrolytes", Polymer Vol. 41, pp. 4531-45362000.

[11] CS. Ramya, S. Selvasekarapandian, T. Savitha "Proton conducting membranes : poly (N-vinyl pyrrolidone) complexes with various ammonium salts", J Solid State Electrochem. Vol. 12 pp. 807-814 2008

[12] R. Mangalam, M. Thamilselvan, S. Selvasekarapandian, S. Jayakumar, R. Manjuladevi,"Polyvinyl pyrrolidone $\mathrm{Mg}\left(\mathrm{ClO}_{4}\right)_{2}$ solid polymer electrolyte: structural and electrical studies, Ionics, vol. 23(10), pp. 2837-2843, 2017.

[13] Abrantes, L. M. "On the Mechanism of Electroless Ni-P Plating". Journal of the Electrochemical Society. Vol. 141 (9), pp. 2356 - 2360, 1994.

[14] VanithaDuraikkan, Asath Bahadur Sultan, Nallamuthu Nallaperumal and Athimoolam Shunmuganarayanan, "Structural, thermal and electrical properties of polyvinyl alcohol/poly(vinyl pyrrolidone)-sodium nitrate solid polymer blend electrolyte" Ionics , vol. 24(1), pp. 139-151, 2018.

[15] S. Rajendran, M. Sivakumar, R. Subadevi, "Investigations on the effect of various plasticizers in PVA-PMMA solid polymer blend electrolytes" Mater. Lett. Vol. 58(5), pp. 641-649, 2004

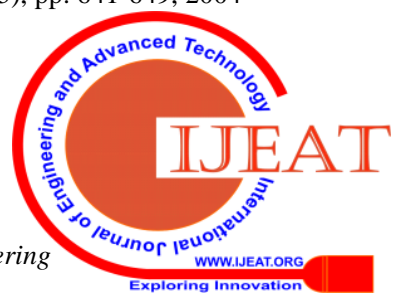




\section{Electrolytes}

[16] . E. M. Abdelrazek, I. S. Elashmawi, H. M. Ragab, "Manifestation of $\mathrm{MnCl} 2$ fillers incorporated into the polymer matrices in their dielectric properties", Physica B, vol. 403, pp. 3097-3104, 2008.

[17] K. H. Wu, Y.R. Wang, W.H. Hwu, "FTIR and TGA studies of poly(4-vinylpyridine-co-divinylbenzene)-Cu(II) complex" Polym. Degrad. Stab. Vol. 79 pp.195-200, 2003.

[18] D. Awanthi De Silva, Buddhika U. Hettiarachchi, L.D.C. Nayanajith, M.D. Yoga Milani and J.T.S. Motha, "Development of a PVP/kappa-carrageenan/PEG hydrogel dressing for wound healing applications” Natn.Sci.Foundation, Sri Lanka, vol. 39 (1), pp. 25-33, 2011.

\section{AUTHORS PROFILE}

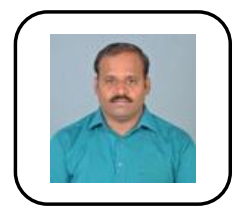

Dr. N. Nallamuthu has obtained his M.Phil. and Ph.D. physics in Pondicherry University, puducherry. Since 2012, he is working as an Associate Professor in Department of Physics, Kalasalingam Academy of Research and Education, Virudhunagar. His area of research mainly focused on solid state ionics, nanomaterials based energy devices. He has published $\sim 20$ research articles in reputed international journals.

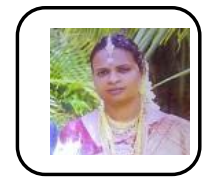

K. Jeya Banu is a Research scholar in the department of Physics, International Research Centre (IRC), Kalasalingam Academy of Research and Education, India. She is research in the area of Polymer Science.

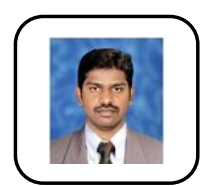

Dr. P. Devendran received his Ph.D degree in Physics from Madras University at Chennai in 2016, developing metal oxides and metal sulfide nano-catalysts for photocatalytic application. After he moved for postdoctoral studies at IRC, Kalasalingam academy of Research and education, he becomes an Assistant Professor of Physics at the same institution and presently began studying metal oxide modified graphene based materials for energy storage device application and their surface science. He published more than 28 research articles and book chapters in reputed journals.

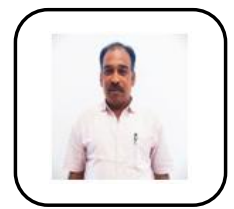

Dr. S. Asath Bahadur is a Senior Professor in the Department of Physics, School of Advanced Sciences at Kalasalingam Academy of Research and Education, India. He has obtained Ph.D. in the area of X-ray crystallography from Madurai Kamaraj University in 1994 and also received his M.Phil. and M.Sc. Degree in physics from Madurai Kamaraj University.He has expertise in the areas of Crystallography and Material science. He has published more than eighty-fivepeer-review research articles in journals of international repute besides seventy more as proceedings. 